\title{
Man biting rate seasonal variation of malaria vectors in Roraima, Brazil
}

\author{
Fábio Saito Monteiro de Barros, Nildimar Alves Honório*/+
}

Departamento de Zoologia, Universidade Federal de Pernambuco, Recife, PE, Brasil *Laboratório de Transmissores de Hematozoários, Instituto Oswaldo Cruz-Fiocruz, Av. Brasil 4365, 21045-900 Rio de Janeiro, RJ, Brasil

\begin{abstract}
Malaria control has been directed towards regional actions where more detailed knowledge of local determinants of transmission is of primary importance. This is a short report on range distribution and biting indices for Anopheles darlingi and An. albitarsis during the dry and rainy season that follows river level variation in a savanna/alluvial forest malaria system area in the Northern Amazon Basin. Distribution range and adult biting indices were at their highest during the rainy season for both An. darlingi and An. albitarsis. During the rainy season the neighboring alluvial forest was extensively flooded. This coincided with highest rates in malaria transmission with case clustering near the river. As the river receded, anopheline distribution range and density decreased. This decrease in distribution and density corresponded to a malaria decrease in the near area. An exponential regression function was derived to permit estimations of An. darlingi distribution over specified distances. Anopheline spatio-temporal variations lead to uneven malaria case distribution and are of important implications for control strategies.
\end{abstract}

Key words: Anopheles darlingi - Anopheles albitarsis - seasonal - distribution - malaria - Brazil

Malaria remains one of the most important infectious diseases in the Americas. Local epidemiological patterns of malaria transmission had their importance recognized leading to new approaches in control strategies (WHO 1997). Consequently, the importance of detailed knowledge of local determinants of transmission and regionally directed actions became of primary importance (Barata 1995).

Roraima is the Brazilian state with one of the highest malaria annual parasitic indices-API in recent years (71.2 in 2004, second for Rondônia with 72.1; 85.4 in 2005, second for Acre with 92.7) (Ministério da Saúde 2006, Fig. 1A). The human population is concentrated around the capital Boa Vista (61\% of 391,317 inhabitants), in 35 agricultural settlements (22\%), and Indian reserves (10\%) (IBGE 2006a). The remaining $7 \%$ of the population live in urban areas represented by small cities and villages (IBGE 2006b).

The most important local vector species have been determined to be An. darlingi Root and An. albitarsis sensu lato. As we have not taxonomically determined the species in the albitarsis complex ourselves, hereinafter the species will be simply referred as $A n$. albitarsis. Nonetheless, previous studies determined the An. albitarsis population in Jardim das Copaíbas, our study area, as An. albitarsis species E (Póvoa et al. 2006). Studies using entomological inoculation rates and

Financial support: the Interamerican Institute for Global Change Research, grant CRN no. 048

+Corresponding author: honorio@ioc.fiocruz.br

Received 17 October 2006

Accepted 5 March 2007 biting indices have implicated An. darlingi and $A n$. albitarsis as the most important vectors in the area (Silva-Vasconcelos et al. 2002, Póvoa et al. 2006).

In this communication we describe seasonal variations in the biting rate of two main local malaria vectors in Jardim das Copaíbas a riverside settlement in the Northern Amazon Basin during one year. An equation describing the distribution range of An. darlingi during the rainy season was also determined.

The study area Jardim das Copaíbas is a rural settlement $\left(02^{\circ} 45^{\prime} 28^{\prime \prime} \mathrm{N}, 60^{\circ} 42^{\prime} 18^{\prime \prime} \mathrm{W}\right)$ by the Branco River $5 \mathrm{~km}$ south of Boa Vista, the capital of the state of Roraima (Fig. 1B). Jardim das Copaíbas can be characterized as a savanna/alluvial forest landscape area. This is because the settlement is located in a savanna in close contact $(\sim 100 \mathrm{~m})$ to a dense alluvial rainforest that delineates the Branco River. The area has a long rainy season (April-November), a short dry season (DecemberMarch), in which the Branco River water levels increase (Póvoa et al. 2006, Fig. 2). During the rainy season, the alluvial forest becomes partly flooded. Average yearly rainfall is $1100-1400 \mathrm{~mm} /$ year and temperatures are permanently high (daily average $27.8^{\circ} \mathrm{C}$ ) with little yearlong variation. Relative humidity is also high (daily average $73.8 \%$ ) and varies little over the year (Furley 1994).

In 2003-2004, Jardim das Copaíbas' 306 inhabitants were distributed in 57 domiciles in $2.66 \mathrm{~km}^{2}$. This corresponds to a density of 115 inhabitants $/ \mathrm{km}^{2}$. Main vegetation among domiciles is low height shrub vegetation characteristic of the savanna. Electric street lighting was present in the area. Malaria is endemic in Jardim das Copaíbas with 53 cases registered in 2004 (Roraima State Health Secretary, pers. commun.).

Four-hour collections (18:00-22:00h) were performed during five nights on each of six occasions bimonthly from August 2003 to July 2004. Mosquitoes were captured on the act of landing on human bait under 


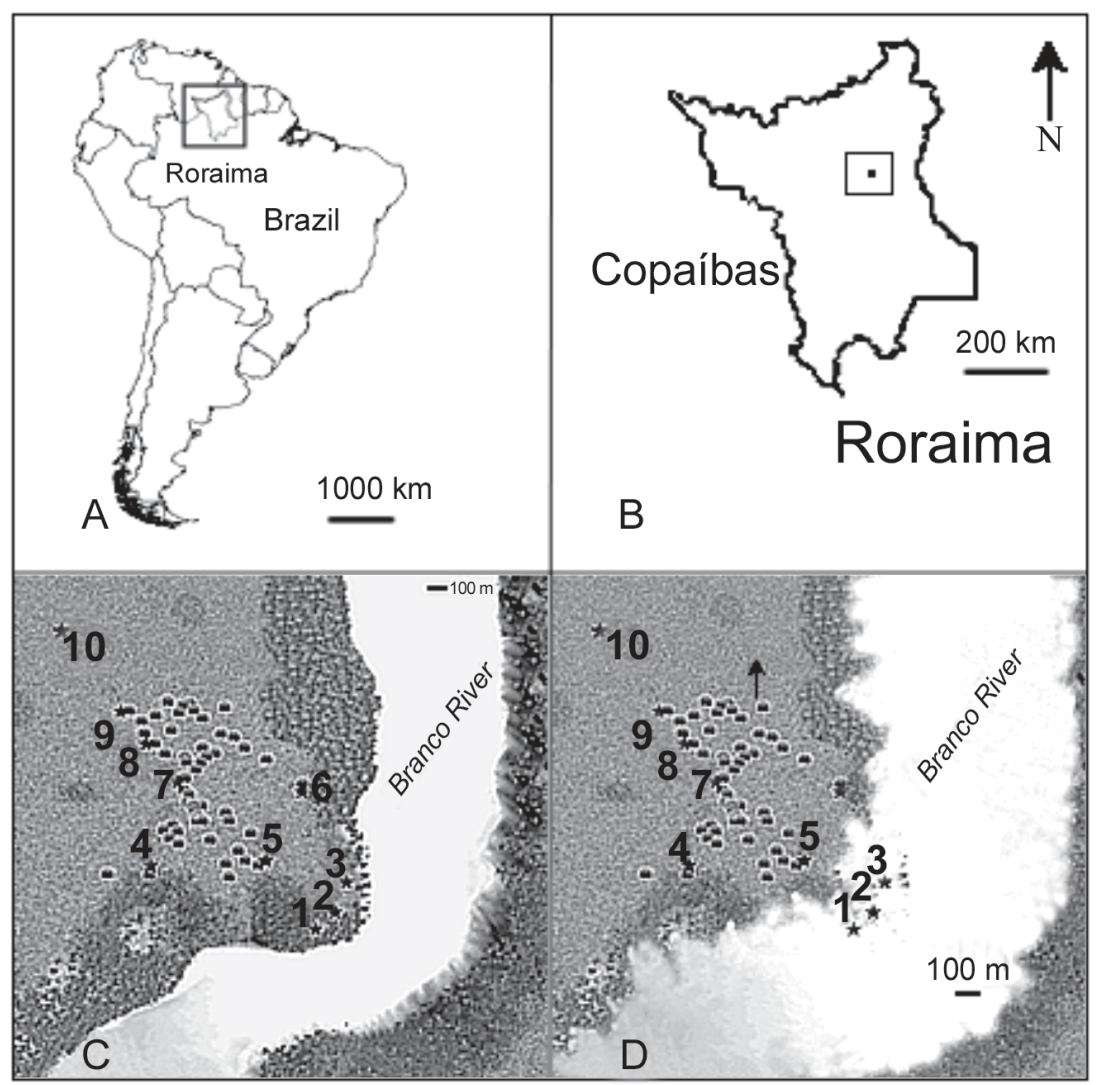

Fig. 1A: South America, Brazil and the state of Roraima in the small rectangle; B: Roraima and Jardim das Copaíbas in the small rectangle; C: the study site in Jardim das Copaíbas and 10 mosquito collecting stations (see Table) during the dry and D: the rainy season.

a protocol approved by the Oswaldo Cruz Foundation's Ethics Committee. Adult mosquitoes were identified using a modified key of Consoli and Lourenço-deOliveira (1994). Ten mosquito collection stations were distributed in the village as shown in Fig. 1C, with one collector at each station. A transect of 10 collections stations were placed at different distances from the river margin during the dry season. Collection stations were at less than $100 \mathrm{~m}$ (stations 1, 2, and 3), $366 \mathrm{~m}, 430 \mathrm{~m}$, $230 \mathrm{~m}, 760 \mathrm{~m}, 1030 \mathrm{~m}, 1200 \mathrm{~m}$, and $1600 \mathrm{~m}$ (stations 4 to 10 , respectively). Rainfall data and river water levels were registered (Fig. 2).

The $1 n+1$ transformed numbers of mosquitoes captured during peak biting activity (the first $4 \mathrm{~h}$ after sunset) were used during the rainy season for deriving an exponential regression function for An. darlingi distribution range. Estimations of the percentages of the adult An. darlingi population that could reach over specified distances were given by the expression:

$$
\mathrm{y}=4.435 \exp \left(\mathrm{x}^{*}-0.003\right)(\mathrm{p}<0.001, \mathrm{r}=0.98)
$$

where $x$ is the distance from the larval habitat and $y$ the percentage of the adult mosquitoes. Since An. albitarsis also has larval habitat dispersed in the open savanna fields, a distribution range function could not be derived from the data collected. It was not possible to determine all larval habitats for each species. The transect represents the closest distance a certain mosquito would have to fly to reach the capture stations.
During the four month-long rainy season from April to July 2003, the Branco River water levels increased from $80 \mathrm{~cm}$ (April 2003) to $300 \mathrm{~cm}$ (July 2003) (mean of $202 \mathrm{~cm}$ for the year 2003, Fig. 2). Following this water level increase the alluvial forest became partially flooded (Fig. 1D), covering collection stations 1, 2, and 3 hence hindering captures at these stations.

Peaks of host-seeking activity were previously determined based on 12-h collections (Barros et al. 2007). An. albitarsis presented one peak, the highest at sunset (18:00-19:00h) in the rainy season, but in dry season can bite throughout the night. An. darlingi showed a peak at sunset (18:00-22:00h) extending activity throughout the night in low numbers arising again to a low peak at sunrise (02:00-06:00h) in rainy season. Thus, the specimens collected by us corresponded to ones that represented the peak of biting activity. Póvoa et al. (2006) in Jardim das Copaíbas demonstrated that An. albitarsis E bites predominantly in the early evening, but can bite throughout the night.

Adult biting indices varied throughout the study period (Table). The posts numbered 1, 2, and 3 become flooded during the rainy season hindering collections at these sites (Fig. 1D). An. darlingi and An. albitarsis highest man biting indices occurred during the rainy season (Table). During the rainy season the Branco River extensively flooded the neighboring alluvial forest, reaching the vicinity of collection station 5 . Then, many 
TABLE

Biting rate for Anopheles darlingi and An. albitarsis in Roraima, Brazil

\begin{tabular}{|c|c|c|c|c|c|c|c|c|c|c|c|c|}
\hline \multirow[t]{2}{*}{$\begin{array}{l}\text { Collection } \\
\text { Station }\end{array}$} & \multicolumn{2}{|c|}{$\begin{array}{l}\text { August } \\
2003\end{array}$} & \multicolumn{2}{|c|}{$\begin{array}{c}\text { November } \\
2003\end{array}$} & \multicolumn{2}{|c|}{$\begin{array}{c}\text { January } \\
2003\end{array}$} & \multicolumn{2}{|c|}{$\begin{array}{l}\text { March } \\
2003\end{array}$} & \multicolumn{2}{|c|}{$\begin{array}{l}\text { May } \\
2003\end{array}$} & \multicolumn{2}{|c|}{$\begin{array}{l}\text { July } \\
2003\end{array}$} \\
\hline & $\begin{array}{c}\text { An. } \\
\text { darlingi }\end{array}$ & $\begin{array}{c}\text { An. } \\
\text { albitarsis }\end{array}$ & $\begin{array}{c}\text { An. } \\
\text { darlingi }\end{array}$ & $\begin{array}{c}\text { An. } \\
\text { albitarsis }\end{array}$ & $\begin{array}{c}\text { An. } \\
\text { darlingi }\end{array}$ & $\begin{array}{c}\text { An. } \\
\text { albitarsis }\end{array}$ & $\begin{array}{c}\text { An. } \\
\text { darlingi }\end{array}$ & $\begin{array}{c}\text { An. } \\
\text { albitarsis }\end{array}$ & $\begin{array}{c}\text { An. } \\
\text { darlingi }\end{array}$ & $\begin{array}{c}\text { An. } \\
\text { albitarsis }\end{array}$ & $\begin{array}{c}\text { An. } \\
\text { darlingi }\end{array}$ & $\begin{array}{c}\text { An. } \\
\text { albitarsis }\end{array}$ \\
\hline 1 & - & - & 3.8 & 20.3 & 2.0 & 11 & 0.1 & 3.0 & - & - & - & - \\
\hline 2 & - & - & 1.8 & 43.0 & 0 & 2.8 & 0.3 & 3.8 & - & - & - & - \\
\hline 3 & - & - & - & - & 0.5 & 7.8 & 0 & 2.8 & - & - & - & - \\
\hline 4 & 9.5 & 17.8 & - & - & 0 & 0 & 0 & 0 & 0.5 & 13.9 & 0.5 & 21.8 \\
\hline 5 & 21.5 & 36.8 & 0.5 & 20.2 & 0.3 & 2.3 & 1 & 3.5 & 1.3 & 5.5 & 5.3 & 19.3 \\
\hline 6 & 16.0 & 17.0 & - & - & 0 & 0 & 0 & 2.5 & 1.9 & 3.1 & 2.0 & 5.0 \\
\hline 7 & 6.8 & 2.3 & 0.5 & 19.3 & 0 & 0.5 & 0 & 0.5 & 1 & 8.3 & 1.3 & 13.0 \\
\hline 8 & 1.5 & 2.8 & 0.0 & 2.8 & 0 & 0 & 0 & 0.5 & - & - & - & - \\
\hline 9 & 1.0 & 5.3 & 0.0 & 1.8 & 0 & 0 & 0 & 0.5 & 0.3 & 7.0 & 0.3 & 14.0 \\
\hline 10 & 0 & 3 & - & - & 0 & 0 & 0 & 0 & 0.3 & 4.5 & 0 & 9.0 \\
\hline
\end{tabular}

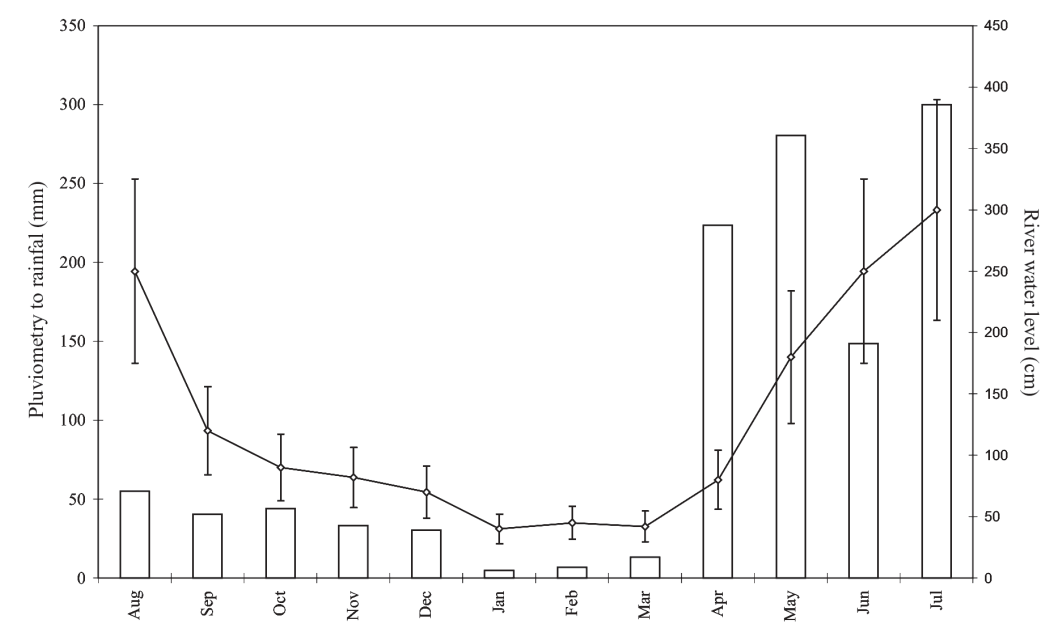

Fig. 2: monthly rainfall (mm) in Boa Vista (bars) and water level (cm) of the Branco River (line) from August 2003 to July 2004.

larval habitats were created being present close to Copaíbas domiciles. This was accompanied by an increase in mosquitoes found in collection stations 5, 6, and 7. As the river receded, less larval habitats were observed and the number of mosquitoes collected was higher in the collection stations closer to the river's margin than the ones located closer to the domiciles.

An. albitarsis larval habitats also occurred in occasional sunlit water collections in the savanna, an ecosystem to which An. albitarsis is well adapted. These larval habitats most probably serve to extend An. albitarsis distribution range further away from the main river. In fact, during the dry season (January 2004) An. albitarsis collections showed a decrease in its distribution range, being captured in stations 1, 2, 3, 5, and 7 only. Malaria transmission was active in Copaíbas in May to July 2003 with 53 cases coincidently with highest biting indices and when the flooded area was at the largest. Then, most malaria cases were clustered near the river close to collection station 5. Station 5 was the collection point where highest man biting indices were observed. Possibly due to cattle farming in the area that would serve as an alternative blood source for anophelines, mosquito collections in areas > $300 \mathrm{~m}$ (stations 4, 5, 7, and 9) from Copaíbas revealed higher biting indices, especially for An. albitarsis.
An. darlingi is the primary malaria vector in the Brazilian Amazon (Deane et al. 1948, Consoli \& Lourenço-deOliveira 1994). Several other species are also implicated as secondary or local vectors (Klein et al. 1991a, b, Póvoa et al. 2006). An. darlingi is strongly associated with the rainforest (Consoli \& Lourenço-de-Oliveira 1994).

Even if we take into account that a mosquito species can fly the same either in the dry or the rainy season, the distribution range of this species would be higher by passive increase in natural larval habitats. An. darlingi can fly up over $7 \mathrm{~km}$ from its release point (Charlwood \& Alecrim 1989), numbers captured at $1 \mathrm{~km}$ distance from rivers are probably low (Roberts et al. 1996). However, mark-release-recapture studies may not adequately predict behavior in a rural environment (Wernsdorfer \& McGregor 1988). Our results show that $20.3 \%$ of the An. darlingi would fly over $500 \mathrm{~m}, 4.6 \%$ would fly over $1000 \mathrm{~m}$, and less than $1 \%$ over $1200 \mathrm{~m}$. This is in the range of the domiciles in Jardim das Copaíbas. Savanna is considered an inhospitable environment for $A n$. darlingi. An. darlingi larval habitats would be preferentially located in the forest (Deane et al. 1948, Deane 1989, Rubio-Palis \& Zimmerman 1997, Tadei \& Thatcher 2000). Indeed, An. darlingi larvae were found in sporadic immature forms collections conducted along 
the margins of streams and shaded rain-water ponds along the alluvial forest. Studies on mark-release-recapture studies would help us to confirm this observation.

In our study, mosquito distribution fluctuates following closely variations in river level. This study of seasonal and spatial mosquito variations may provide important implications to direct control strategies. The recognition of uneven case distribution in malaria-endemic areas and the determination of its causal factors could lead to improved use of resources from malaria control programs.

\section{ACKNOWLEDGEMENTS}

To the technicians of Fundação Nacional de Saúde of Roraima. To Marieta Braks and Tamara Lima-Camara for comments and critical review of the manuscript.

\section{REFERENCES}

Barata RCB 1995. Malaria no Brasil: panorama epidemiológico na última década. Cad Saú Púb 11: 128-136.

Barros FSM, Arruda ME, Vasconcelos SD, Luitgards-Moura JF, Confalonieri U, Rosa-Freitas, Tsouris P, Lima-Camara T, Honório NA 2007. Parity and age composition for Anopheles darlingi Root (Diptera: Culicidae) and Anopheles albitarsis Lynch-Arribalzaga (Diptera: Culicidae) of the Northern Amazon Basin, Brazil. J Vector Ecol in press.

Charlwood JD, Alecrim WA 1989. Capture-recapture studies with the South American malaria vector Anopheles darlingi, Root. Ann Trop Med Parasitol 83: 569-576.

Consoli RAGB, Lourenço-de-Oliveira R 1994. Principais Mosquitos de Importância Sanitária no Brasil, Fiocruz, Rio de Janeiro, $225 \mathrm{pp}$.

Deane LM 1989. A cronobiologia da descoberta dos transmissores da malária na Amazônia brasileira. Mem Inst Oswaldo Cruz 84: 149-156.

Deane LM, Causey OR, Deane MP 1948. Notas sobre a distribuição e a biologia dos anofelinos das Regiões Nordestina e Amazônica do Brasil. Rev Serv Esp Saú Púb 1: 827-965.

Furley PA 1994. The Forest Frontier, Routledge, London, 235 pp.

IBGE-Instituto Brasileiro de Geografia e Estatística 2006a. Avail- able at http,//www.ibge.gov.br/servidor_arquivos. Accessed 12 June 2005

IBGE-Instituto Brasileiro de Geografia e Estatística 2006b. Available at http,//www.ibge.gov.br/cidadesat/default.php. Accessed 12 June 2005.

Klein TA, Lima JB, Tada MS, Miller R 1991a. Comparative susceptibility of anopheline mosquitoes in Rondônia, Brazil to infection by Plasmodium vivax. Am J Trop Med Hyg 45: 463-470.

Klein TA, Lima JB, Tada MS 1991b. Comparative susceptibility of anopheline mosquitoes to Plasmodium falciparum in Rondônia, Brazil. Am J Trop Med Hyg 44: 598-603.

Ministério da Saúde 2006. A malária no Brasil. Available at http/ /portal.saude.gov.br/portal/arquivos/pdf/be_malaria_01_2005.

Póvoa MM, Souza RTL, Lacerda RNL, Rosa ES, Galiza D, Souza JR, Wirtz RA, Schlichting CJ, Conn JE 2006. The importance of Anopheles albitarsis and An. darlingi in human malaria transmission in Boa Vista, state of Roraima, Brazil. Mem Inst Oswaldo Cruz 101: 163-168.

Roberts DR, Manguin S, Harbach RE, Woodruff R, Rejmankova E, Polanco J, Wullschleger B 1996. Predictions of malaria vectors distributions in Belize based on multispectral satellite data. Am J Trop Med Hyg 54: 302-308.

Rubio-Palis Y, Zimmerman RH 1997. Ecoregional classification of malaria vectors in the Neotropics. J Med Entomol 34: 499-510.

Silva-Vasconcelos A, Kato MY, Mourão EN, de Souza RT, Lacerda RN, Sibajev A, Tsouris P, Póvoa MM, Momen H, Rosa-Freitas MG 2002. Biting indices, host-seeking activity and natuaral infection rates of anopheline species in Boa Vista, Roraima, Brazil from 1996 to 1998. Mem Inst Oswaldo Cruz 97: 151-161.

Tadei WP, Thatcher BD 2000. Malaria vectors in the Brazilian Amazon: Anopheles of the subgenus Nyssorhynchus. Rev Inst Med Trop São Paulo 42: 87-94.

Wernsdorfer WH, McGregor I 1988. Malaria: Principles and Practice of Malariology, Churchill Livingstone, Edinburgh $1818 \mathrm{pp}$.

WHO-World Health Organization 1997. World malaria situation in 1994. WHO Weekly Epidem Rec 22: 161-167. 